\title{
HERMENEUTIKA OTORITATIF KHALED M. ABOU EL FADL: METODE KRITIK ATAS PENAFSIRAN OTORITARIANISME DALAM PEMIKIRAN ISLAM
}

\author{
Nasrullah \\ STAI Auliaurrasyidin, Jl. Gerilya Parit 6 Tembilahan-Riau \\ e-mail: anasbanjar@plasa.com
}

\begin{abstract}
This paper deals with Abou El Fadl's hermeneuticalauthoritative concept. The hermeneutical athouritative emerges as an anti-thesis to all authoritative-interpretative concepts in Islamic thought. The authoritative- interpretative concept established on God's name interpretation. This kind of interpretation claims that interpretation is an absolute right, without comropmizing with the interpretation of meaning with values of justice and contemporary issues of humanity, such as gender, jihâd issue and practice of democracy concept in Moslem countries.

$$
\begin{aligned}
& \text { يتناول هذا البحث نظرية الهرمنيوطيقا لدى أبى الفضل ، حيث بعتبر البعض } \\
& \text { أن هذه النظرية على عكس نظرية أوتوريتاتيف وهى نوع من مناهج التفسير } \\
& \text { باسم الإله. و هذا المنهج الأخير يدعى أن التفسير الذى يسير عليه ما جاء إلا } \\
& \text { بالحق المطلق فلا يحتاج إلى اللجوء إلى توضيح المعانى من خلال القضايا } \\
& \text { المعاصرة فى العدالة و الإنسانية ، و على سبيل المثال : قضية الجندر و مسألة } \\
& \text { معانى الجهاد و تطبيق نظام الديموقر اطية فى الدول الإسلامية. }
\end{aligned}
$$

Kata Kunci: hermeneutika otoritatif, penafsiran otoritarianisme, pemikiran Islam, hukum Islam, jender 


\section{PENDAHULUAN}

Kemunculan Khaled M. Abou El Fadl dengan salah satu karyanya, Speaking in God's Name: Islamic Law, Authority, and Women, telah menunjukkan betapa penting pendekatan hermeneutika bagi studi-studi keislaman, khususnya dalam studi hukum Islam. Hermeneutika menurutnya bukanlah suatu metode pendekatan yang dapat "merusak" tatanan konstruksi studi-studi keislaman, tetapi hermeneutika dapat menjadi suatu "pupuk organik" yang dapat menyegarkan dan menyuburkan pemahaman terhadap ilmu-ilmu keislaman yang telah terbakukan secara formal dalam bentuk teks kitab suci dan kitab-kitab karya para ulama klasik. Hermeneutika dipergunakan supaya pemahaman terhadap ilmu-ilmu keislaman itu agar bisa terus dinamis dan hidup dari masa ke masa ( $s \square$ alih li kulli zamân wa makân) sesuai dengan perkembangan ruang dan waktu.

Hermeneutika diperlukan sebagai metode pendekatan di samping pendekatan dalam tradisi Islam sendiri dan dibantu oleh perangkat metodologi keilmuan mutakhir seperti linguistik, kritik literatur, sejarah, dan ilmu-ilmu sosial humaniora lainnya yang bisa mendukung bagi terciptanya suatu pemahaman yang komprehensif. Tawaran yang kurang lebih persis dalam menyikapi keharusan adanya sebuah "dialog" antara ilmu-ilmu keislaman dengan ilmu-ilmu sosial dan humaniora juga dilontarkan oleh Arkoun (2002:295). Hermeneutika yang ditawarkan Abou El Fadl adalah suatu pendekatan yang berfungsi sebagai media "negosiasi" antara komponen teks, pengarang, dan pembaca dalam menentukan kompetensi otentisitas teks, penentuan makna dinamis teks, dan komitmen moral pembaca dalam memahami maksud teks. Dalam kaitan inilah, tulisan ini bermaksud mengungkap pemikiran Khaled Abou El Fadl tentang metode kritik atas penafsiran otoritarianisme dalam pemikiran Islam.

BIOGRAFI DAN LATAR BELAKANG KULTUR INTELEKTUAL KHALED M. ABOU EL FADL

Nama lengkapnya adalah Khaled Medhat Abou El Fadl. Ia dilahirkan di Kuwait pada tahun 1963. Kedua orang tuanya yang berdarah Mesir. Pendidikan dasar dan menengahnya, ia tamatkan di negeri kelahirannya, Kuwait. Kemudian pendidikannya dilanjutkan di Mesir. Sebagaimana tradisi bangsa Arab yang memegang teguh tradisi 
hafalan, Abou El Fadl kecil sudah hafal Alquran sejak usia 12 tahun. Ayahnya yang berprofesi sebagai seorang pengacara, sangat menginginkan Abou El Fadl menjadi seorang yang menguasai hukum Islam. Ayahnya sering mengujinya dengan pertanyaan-pertanyaan seputar masalah hukum. Setiap liburan musim panas, Abou El Fadl menyempatkan menghadiri kelas-kelas Alquran dan ilmu-ilmu syariat di Masjid Al-Azhar, Kairo, khususnya dalam kelas yang dipimpin oleh Shaykh Muh $\square$ ammad al-Ghazâlî (w. 1995), tokoh pemikir Islam moderat dari barisan revivalis yang ia kagumi (Mizrawi, 2005:15).

Sebagai pemuda yang dibesarkan dalam kondisi sosial politik Mesir yang masih labil, Abou El Fadl sebagaimana halnya rakyat Mesir pada umumnya, mengalami kekecewaan atas akibat kegagalan pan-Arabisme dalam perang 1967 yang berpengaruh sesudah masa tersebut bagi rakyat Mesir dan bangsa-bangsa Arab pada umumnya. Atas kekalahan inilah kemudian bangsa Arab, khususnya Mesir, melakukan suatu "introspeksi sejarah dan kultur" Arab dengan meninjau ulang apa yang dinamakan sebagai turâth atau tradisi yang betumpu pada al-aslah (otentisitas) dan berhadapan dengan tantangan al-mu'asarah (modernitas), terutama kegelisahan yang dialami oleh kalangan intelektual (Asmin dalam Hanafi, 2001:xii; Assaukanie, 1998:61). Kekalahan tersebut berdasarkan opini umum menurut Abou El Fadl (2003b:18), terutama dipengaruhi oleh gurunya Shaykh Jalâl Kishk, sama halnya dengan kekalahan spritual sekaligus intelektual bangsa Arab muslim. Pada tahun 1973, akhirnya bersama dengan kelompok Ikhwan Muslimin berhasil mengusir tentara Israel dari daerah Sinai.

Menurut pengamatan Abou El Fadl, kemenangan yang diraih Ikhwan Muslimin bukanlah suatu kemenangan yang gemilang, tetapi lambat laun membawa pengorbanan besar-besaran bangsa Arab. Di satu sisi memang mendatangkan rezeki berlimpah bagi negara Arab penghasil minyak, begitu juga kalangan elit Mesir yang korup. Namun demikian, di sisi lain menyebabkan kondisi chaos bagi negara Arab secara umum, baik sosial maupun politik (Abou El Fadl, 2003b: 20). Kondisi ini juga merambat dalam ruang lingkup keagamaan yang bergeser ke arah tatarruf al-dînî (ekstremisme agama), terutama pusatpusat intelektual Arab. Tidak terkecuali adalah lembaga Al-Azhar, yang telah dikuasai mainstream konservatisme Islam. 
Pada tahun 1982, Abou El Fadl meninggalkan Mesir menuju Amerika dan melanjutkan studinya di Yale University dengan mendalami ilmu hukum selama empat tahun dan dinyatakan lulus studi bachelor-nya dengan predikat cumlaude. Tahun 1989, ia menamatkan studi Magister Hukum pada University of Pennsylvania. Atas prestasinya itu, ia diterima mengabdi di Pengadilan Tinggi (Suppreme Court Justice) wilayah Arizona, sebagai pengacara bidang hukum dagang dan hukum imigrasi. Dari sinilah kemudian Abou El Fadl mendapatkan kewarganegaraan Amerika, sekaligus dipercaya sebagai staf pengajar di University of Texas di Austin. Kemudian ia melanjutkan studi doktoralnya di University of Princeton. Pada tahun 1999, Abou El Fadl mendapat gelar Ph.D dalam bidang hukum Islam. Sjak saat hingga sekarang, ia dipercaya menjabat sebagai profesor hukum Islam pada School of Law, University of California, Los Angeles (UCLA).

Abou El Fadl adalah penulis yang produktif, dan karena karyakaryanya tersebutlah yang melambungkan namanya dan diperhitungkan dalam blantika diskursus intelektual, baik di Amerika maupun di dunia Islam. Di antara karya-karyanya yang sudah diterbitkan dalam bentuk buku adalah: Speaking in God's Name: Islamic Law, Authority and Woman, Rebellion and Violence in Islamic Law, And God Knows the Soldiers: The Authoritative and Authoritarian in Islamic Discourse, The Authoritative and Authoritarian in Islamic Discourses: A Contemporary Case study, Islam and Challenge of Democracy, The Place of Tolerance in Islam, Conference of Books: The Search for Beauty in Islam. Karya-karyanya di atas pada umumnnya sudah banyak yang diterjemahkan ke bahasa Indonesia. Di samping itu, tentu masih banyak lagi tulisan ilmiah Abou El Fadl yang lain, baik dalam bentuk artikel maupun jurnal ilmiah (Billa, 2005).

Di tengah-tengah kesibukannya sebagai profesor, Abou El Fadl sering diundang dan mengisi seminar, simposium, lokakarya dan talk show di televisi dan radio seperti CNN, NBC, PBS, NPR, dan VOA. Belakangan ia banyak memberikan komentar tentang isu otoritas, terorisme, toleransi dan hukum Islam. Ia juga pernah menjabat direktur Human Right Watch dan anggota Komisi Kebebasan Beragama, Amerika Serikat (Misrawi, 2005:17). 


\section{KEGELISAHAN TERHADAP KONSTRUKSI OTORITARIANISME DALAM PEMIKIRAN ISLAM}

Secara normatif, teks-teks keagamaan memberikan ruang cukup lebar bagi berbagai variasi pemahaman (multi tafsir/ikhtilaf). Beragam proses pemahaman dan penafsiran bertujuan untuk menguak "kehendak" Tuhan. Karena teks adalah medium otoritatif yang mendokumentasikan "kehendak" Tuhan, setiap penafsir berusaha menggapai hingga mencapai kebenaran otoritatif itu. Dalam posisi segala kemungkinan suatu bentuk penafsiran, maka akan bisa memunculkan beragam penafsiran lain. Sang penafsir bisa saja terkadang terjebak dalam kubangan otoritarianisme atau absolutisme, manakala ia melampaui kewenangan dengan mengidentikkan teks ke dalam sifat dirinya. Dengan pengertian yang lain, sang penafsir tersebut memposisikan diri sebagai "juru bicara" teks atau Tuhan (Sirry, 2005:28).

Konsekuensi tak terhindarkan ialah sang penafsir tersebut menutup kemungkinan makna lain, karena memposisikan dirinya telah merepresentasikan makna yang dikehendaki oleh Tuhan. Dalam konteks ini Abou El Fadl menyebut sikap otoritarian sebagai sikap "merampas kehendak Tuhan". Sinyalemen penutupan pintu ijtihad menurut Abou El Fadl merupakan contoh dinamika sempurna dalam wujud nyata sikap otoritarianisme dalam pemikiran hukum Islam. Dalam istilah yang lain Abou El Fadl menyebutkan bahwa otoritarianisme adalah tindakan "mengunci" kehendak Tuhan, atau kehendak teks, dalam sebuah penetapan tertentu yang statis, dan menyajikan pendapat itu sebagai sesuatu yang pasti, absolut, dan menentukan (Misrawi, 2005:14).

Menurut analisis Abou El Fadl, fenomena otoritarianisme dalam pemikiran Islam, khususnya dalam penelitiannya tentang diskursus hukum Islam, merupakan akibat dari kesalahan dalam menempuh prosedur metodologis yang terkait dengan relasi antara ketiga unsur pengarang, teks, dan pembaca. Seorang pembaca yang mengunci teks dalam sebuah makna tertentu, maka ia telah merusak integritas pengarang dan teks itu sendiri.

Sama halnya dengan ungkapan orang yang mengatakan dengan arogannya, "Saya tahu apa yang dikehendaki oleh pengarang, dan saya tahu apa yang dinginkan oleh teks. Pengetahuan saya bersifat 
menentukan dan meyakinkan". Ungkapan ini sekaligus merupakan penetapan, tetapi hakikatnya mengakhiri peran pengarang dan "membatasi" dinamika dalam konteks penggalian pemahaman dari sebuah teks (Abou El Fadl, 2003a:205).

Dalam dimensi penafsiran otoritarianisme, problem yang paling dominan dan menentukan adalah pada tingkat pembaca (reader). Ketika seorang pembaca berjibaku dengan teks dan menarik kesimpulan hukum atau sebuah pemahaman dari teks tersebut, maka resiko yang dihadapi oleh pembaca adalah pembaca menyatu dengan teks, atau penetapan pembaca akan menjadi perwujudan ekslusif teks tersebut. Dalam proses ini, teks tunduk pada pembaca dan secara efektif pembaca menjadi pengganti teks (Billa, 2005:90).

Dalam tataran ini, poros objektif teks (otoritatif) dan poros subjektif (pembaca) saling bermain. Memang harus diakui, segala proses penafsiran atau pemahaman tidak bisa dilepaskan dari unsur subjektifisme, apapun bentuknya proses pemahaman yang dilakukan. Baik yang berasal dari individu maupun secara kolektif yang melibatkan sebuah institusi dengan klaim sebagai pemegang hak penafsir kehendak Tuhan. Akan tetapi menurut Abou El Fadl, penafsiran yang terlalu subjektif, bisa jatuh ke dalam jeratan otoritarianisme (Abou El Fadl, 2003a:207).

Abou El Fadl mencontohkan fenomena mutakhir dari praktek otoritarianisme tersebut yang terjadi pada gerakan puritanisme Islam Wahabi. Gerakan yang bermarkas di Saudi Arabia ini mendapat dukungan pemerintah sebagai kekuatan politik, yang tendensinya untuk menutup gerak dinamika teks, sehingga hanya tersisa kebenaran tunggal. Geneologi fundamentalisme dari gerakan teologi dan mazhab-mazhab fikih yang bersikap anti toleransi dan pluralisme bisa dilacak dari tendensi ini. Mereka, baik secara individu maupun kelompok telah merasa memonopoli kebenaran, sementara pendapat orang lain tidak mungkin diakomodasi. Mereka berposisi sebagai pemegang kebenaran dan karenanya berhak untuk melakukan value judgment atas kelompok lain sebagai "tidak Islam", sesat, kafir dan seterusnya (Sirry, 2005:30).

Begitu juga yang terlihat, menurut Abou El Fadl, dalam bidang hukum Islam dengan produk hukum fatwa yang dikeluarkan oleh lembaga fatwa resmi di Saudi Arabia dengan nama singkatan CRLO (Council for Scientific Research and Legal Opinions). Lembaga yang 
bersifat ekslusif ini telah mengaku serta mengasumsikan kelompok mereka sebagai wakil dan "juru bicara" Tuhan. Menurut Abou El Fadl, fatwa-fatwa yang dikeluarkan telah banyak yang merendahkankan kedudukan perempuan atau bias jender yang sangat bertentangan dengan nilai-nilai yang terdapat dalam Alquran tentang kesetaraan manusia tanpa memandang jenis kelamin.

Ada dua alasan Abou El Fadl yang mendasarinya mengambil produk fatwa-fatwa Wahabi sebagai bahan analisis hermeneutiknya. Pertama, produk intelektual para ahli hukum dari mazhab tersebut melambangkan bentuk otoritarianisme interpretatif; dan kedua, mazhab (baca fumdamentalisme) ini telah menjadi mazhab yang dominan di dunia Islam dewasa ini (Romli, 2005:46).

Menurut Abou El Fadl, seruan mereka kembali kepada Islam murni, (Al-rujû' ilâ al-Qur'ân wa al-Sunnah) asli, dan tidak berubah, jelas sekali tidak masuk akal. Pendekatan mereka bersifat ahistoris, terbukti naif dan simplistis. Menurutnya tidak mungkin kembali kepada Alquran dan sunah dalam kevakuman. Seharusnya dalam kritik Abou El Fadl, kembali kepada keduanya berarti kembali kepada sumber-sumber klasik yang mengomentari konteks dan makna ayat tersebut (asbâb al-nuzûl dan asbâb al-wurûd). Sekaligus menjelaskan kumpulan dokumentasi teks Alquran, dan kembali kepada sumbersumber klasik yang menghimpun sunah, menguji kesahihannya, serta menjelaskan konteks dan menafsirkan hadis-hadis nabi dan para sahabatnya secara kontekstual.

Kecenderungan para ulama Wahabi yang anti tradisi intelektual dan mengambil kesimpulan hukum melalui jalan pintas dengan dalih kembali kepada Alquran dan sunah secara tekstual. Sehingga metode mereka sangat selektif, tidak sistematis dan oportunis. Yang lebih parah lagi adalah klaim kebenaran mereka dengan anggapan bahwa hukum inilah yang pasti dan absolut, sebagai kesimpulan hukum yang "dikehendaki” oleh Tuhan (Abou El Fadl, 2003a:253). Di sinilah sesungguhnya teridentifikasi bahwa tafsiran mereka bersifat otoritarianisme. Kegelisahan ini yang mendorong Abou El Fadl untuk melakukan tawaran metodologi hermeneutika otoritatif sebagai kritik dan "lawan" dari metodologi hermeneutika otoritarianisme, khususnya yang dipakai para ulama Wahabi dan kalangan fundamentalisme Islam pada umumnya. 


\section{TAWARAN HERMENEUTIKA OTORITATIF KHALED M. ABOU EL FADL}

Abou El Fadl dalam menawarkan metodologi hermeneutikanya, menyajikan kerangka konseptual untuk membangun gagasan tentang otoritas dan otoritarian dalam Islam. Pembahasan otoritas menurut Abou El Fadl sangat penting karena tanpa otoritas maka kita akan beragama secara relatif, subjektif dan individual. Ada tiga pokok persoalan yang menjadi kunci dalam membuka diskursus yang otoritatif dan otoriter dalam Islam, yaitu :

Pertama, mengenai kompetensi (otentisitas). Yang dimaksud adalah bagaimana mengetahui bahwa suatu perintah adalah benarbenar datang dari Tuhan dan nabi-Nya. Teks-teks yang memiliki kompetensi dinilai otoritatif, sedangkan yang tidak memiliki kompetensi tidak dinilai sebagai yang otoritatif dan mewakili "suara" Tuhan dan nabi.

Penggunaan teks-teks yang tidak otoritatif akan menjerumuskan manusia pada otoritarianisme. Dalam konteks kompetensi Alquran, Abou El Fadl menyatakan dengan landasan iman, bahwa Alquran adalah firman-firman Allah yang abadi dan terpelihara kemurniannya. Kompetensi Alquran tidak usah diganggu gugat. Tampaknya Abou El Fadl di sini bersikap tradisional dengan tidak berspekulasi melakukan perdebatan panjang tentang kemurnian dan keaslian Alquran, karena baginya yang relevan adalah bagaimana menentukan makna dari Alquran tersebut (Abou El Fadl, 2003a:128).

Atas dasar itu, persoalan kompetensi (otentisitas) hanya berlaku pada sunah, tidak pada Alquran. Kompetensi sunah perlu dikaji ulang dan dipertanyakan agar benar-benar otoritatif bisa mewakili "suara" nabi sebagai sumber otoritas setelah Alquran. Abou El Fadl dalam membahas kompetensi sunah menggunakan metodologi kritik hadis klasik (mustalah al-hadith) dari kritik transmisi (naqd al-sanad) dan kritik perawi ('ilm al-rijâl dan al-jarh wa al-ta'dîl). Hal yang lebih penting menurut Abou El Fadl, kajian hadis harus menyentuh realitas sejarah. Dengan mengembangkan kajian pada kritik matan (naqd almatn) yang memungkinkan seseorang mengkaji konteks sosio-historis hadis untuk landasan kontekstualisasi pada masa kekinian. Serta yang terpenting juga menurut Abou El Fadl ialah, membaca fenomena dari riwayat hadis dengan berlandaskan kepada peran nabi, bukan 
mengatakan bahwa nabi telah mengatakan sesuatu hadis, tetapi peran apa yang dimainkan oleh nabi dalam sebuah riwayat tersebut (Abou El Fadl, 2003a:130).

Pemahaman peran sosok nabi itu akan melahirkan perbedaan fungsi pada sunah, jika nabi melakukan sebagai sosok manusia biasa, maka sunah itu tidak memiliki otoritas sebagai sumber hukum, namun jika sebaliknya, nabi memerankan sebagai utusan Tuhan yang harus diikuti, maka sunah tersebut memiliki otoritas untuk diikuti. Selain itu Abou El Fadl menegaskan perlu membedakan antara hadis yang mutawâtir dan ahad yang berbeda dalam kadar otoritasnya bagi persoalan legislasi dan tindakan hukum.

Kedua, mengenai penetapan makna. Maksudnya, bagaimana menetapkan makna dari kehendak Tuhan yang termaktub dalam teks otoritatatif tersebut. Ketika sebuah teks lahir, ia telah memiliki eksistensi dan integritasnya sendiri. Teks dalam hal ini bersifat otonom (Billa, 2005:94). Otonomi teks memberikan kemungkinan pembacaan yang hidup dan memberikan peluang bagi berbagai model pembacaan. Banyak teks yang "mati" di tangan pengarang dan pembaca. Karena itulah hubungan antara pengarang, teks, dan pembaca harus berimbang dan proporsional dalam proses penentuan makna (Palmer, 2003:98; Bleicher, 2003; Abu Zayd, 1994). Dominasi salah satunya akan mengakibatkan pembacaan yang bersifat otoriter. Manusia di hadapan teks adalah artikulator sekaligus interpretator teks. Memposisikan manusia sebagai subjek, bukan tanpa masalah, malah bisa sebaliknya, dan menjadikan teks sangat inferior di hadapan subjek pembaca berdasarkan kepentingan dan ideologi yang dibawa oleh pembaca dengan unsur subjektifitasnya.

Untuk itu, menurut Abou El Fadl (2003a:185), dibutuhkan keseimbangan kekuatan yang harus ada antara maksud pengarang, teks, dan pembaca. Atau yang ia istilahkan dengan hermeneutika berbasis negosiasi antara ketiga unsur triadik di atas (Palmer, 2003:97). Penetapan makna berasal dari proses yang kompleks, interaktif, dinamis, dan dialektis antara ketiga unsur tersebut, tanpa saling mendominasi. Penafsiran yang tepat dalam menentukan makna adalah penafsiran yang menghormati peranan, otonomi, dan integritas teks. Menghormati otonomi teks berarti bertujuan menghindari kooptasi dan otoritarianisme pembaca terhadap teks sehingga teks bisa ditafsirkan sesuai dan sebebas-bebasnya. 
Atas dasar itu, Abou El Fadl menegaskan gagasan teks yang terbuka (the open text). Alquran dan sunah merupakan "karya" yang terus berubah (work in movement). Teks keduanya dapat saja bersifat statis, tetapi isi dan kandungan dari teks tersebut tetap bergerak dan menerima, bahkan menyediakan bentuk penafsiran yang beragam (Abou El Fadl, 2003a:212). Sebagai teks terbuka, Alquran bukan hanya menghalalkan beragam interpretasi, melainkan juga mendorong proses keterlibatan dinamis, di mana teks mempunyai kedudukan sentral. Dengan kata lain, menempatkan Alquran sebagai teks terbuka, menurut Abou El Fadl, Alquran akan tetap relevan dan terus memiliki suara dalam ruang dan waktu yang berbeda (Sirry, 2005:29). Bandingkan dengan konsep Mohammed Arkoun (1994:57) tentang "korpus terbuka", sebagai antitesa terhadap "korpus resmi tertutup."

Selain persolan penetapan makna tersebut, Abou El Fadl juga memaparkan persoalan penting lain, yaitu persoalan pembuktian yang mendasari pengambilan kesimpulan hukum. Pembuktian itu terkait dengan "asumsi dasar" dalam komunitas interpretasi yang berbedabeda. Ada empat asumsi dasar yang berfungsi sebagai landasan dalam membangun analisis hukum, yaitu: (1) asumsi berbasis nilai yang lebih bersifat substansi normatif, (2) asumsi berbasis metodologis yang lebih bersifat prosedur ilmiah, (3) asumsi berbasis iman yang lebih bersifat teologis sesuai karakteristik pesan Tuhan dan tujuannya, (4) asumsi berbasis akal yang lebih bersifat nalar rasionalistik (Abou El Fadl, 2003a:227).

Ketiga, berkaitan dengan konsep perwakilan dalam Islam. Dalam ajaran Islam, kedaulatan mutlak hanya milik Tuhan, namun di sisi lain, Islam juga memiliki konsep kekhalifahan manusia sebagai perwakilan Tuhan. Akan tetapi pelimpahan wewenang atau otoritas Tuhan kepada manusia akan membuka ruang bagi otoritarianisme, jika tidak dilengkapi syarat-syarat tertentu. Menurut Abou El Fadl ada beberapa prasyarat standar kepada mereka yang disebut sebagai "wakil khusus" Tuhan. Secara umum manusia adalah wakil (khalifah) Tuhan di bumi. Namun pelimpahan wewenang Tuhan selalu diwakili dan dinegoisasi oleh manusia yang akan ditempuh dalam proses pemahaman.

Ada lima syarat sebagai pelimpahan otoritas Tuhan kepada manusia sebagai "wakil khusus" dalam tindakan menafsir, yaitu: pertama, jujur (honesty), dalam memahami perintah Tuhan; kedua, 
kesungguhan (diligence) dengan dipastikan telah mengerahkan segenap kemampuan rasionalnyanya (ijtihad) dalam memahami perintah Tuhan; ketiga, kemenyeluruhan (comprehensiveness) dengan dipastikan telah melakukan penyelidikan secara menyeluruh untuk memahami kehendak Tuhan; keempat, rasionalitas (rasionality) dengan dipastikan telah melakukan upaya pemahaman dan penafsiran terhadap perintah Tuhan secara rasional; dan kelima, pengendalian diri (self-restraint) dengan dipastikan upaya yang dilakukan dalam memahami dilandaskan pada sikap batin dengan dasar rendah hati dan pengendalian diri, tidak bersikap emosional dalam menjelaskan kehendak Tuhan (Abou El Fadl, 2003a:99).

Berangkat dari metodologi hermeneutika otoritatif inilah, Abou El Fadl mengkritik penafsiran dan sistem pengambilan produk hukum (istinbât $\square$ al-ahkâm) yang tertuang dalam bentuk fatwa yang dikeluarkan oleh CRLO di Saudi Arabia yang merupakan "made in" lembaga hukum Wahabi sebagai mazhab resmi terhadap persoalan penafsiran terhadap perempuan yang bias jender. Hal yang sangat mengkhawatirkan adalah hasil dari fatwa ini telah tersebar luas di belahan dunia, karena kecanggihan dunia informasi dan teknologi. Hal yang lebih merisaukan lagi adalah karena hal ini terjadi dalam konteks masyarakat muslim yang hidup sebagai minoritas yang tinggal di dunia Barat.

Fatwa-fatwa keagamaan yang menyangkut kehidupan perempuan yang dianggap problematis oleh Abou El Fadl antara lain ialah fatwa keagamaan Islam tentang pelarangan perempuan mengunjungi makam suami, perempuan mengeraskan (jahr) dalam berdoa, perempuan menyetir kendaraan, dan perempuan harus didampingi mahram-nya dalam melakukan segala perjalanan dan sebagainya. Tentu saja kasus-kasus di atas adalah bentuk pelarangan yang tidak relevan lagi di saat sekarang dengan era keterbukaan dan partisipasi semua kalangan, termasuk perempuan dalam sektor publik.

Fatwa-fatwa tersebut dianggap Abou El Fadl sebagai tindakan "perendahan" bahkan sebagai bentuk "penindasan" terhadap perempuan yang tidak dapat ditoleransi dalam konteks saat ini (Amin Abdullah dalam Abou El Fadl, 2004:vii). Fatwa-fatwa yang berlindung di bawah dan atas nama teks (nass), telah diklaim bahwa itulah yang sebenarnya "dikehendaki" oleh Tuhan. Oleh karena itu, ia 
bersifat absolut sehingga harus diikuti menurut lembaga fatwa Wahabi ini.

Begitu juga pendapat atau fatwa keagamaan yang dikeluarkan oleh CRLO dengan pernyataan bahwa, perempuan harus berdoa atau melakukan shalat di suatu tempat yang sangat tersembunyi agar tidak tampak oleh laki-laki, perempuan harus menyerahkan jiwa dan raganya kepada suami kapan pun sang suami menghendaki dalam konteks berhubungan badan, keselamatan perempuan di akhirat nanti bergantung kepada kepuasan dan keinginan suami dalam hubungan seksual, perempuan akan mengisi sebagai besar atau mayoritas penghuni neraka, perempuan lebih rendah tingkat intelektualnya daripada laki-laki, perempuan pembawa sial, dan sebagainya (Abou El Fadl, 2003a:325).

Fatwa-fatwa ini dalam kajian Abou El Fadl, jelas telah jatuh pada dimensi penafsiran yang otoriter (despotic). Karena wataknya yang mengklaim sebagai tafsiran yang benar dan tunggal, dan terdapat tindakan "mengunci" teks yang seharusnya bisa dipahami secara terbuka sesuai dengan konteks di mana penafsiran dilakukan, sehingga tidak dimungkinkan lagi adanya penafsiran lain. Di samping juga pemilihan teks tidak bersifat otoritatif. Sebab hadis-hadis yang dipakai oleh lembaga fatwa CRLO, menurut Abou El Fadl tergolong hadis-hadis kategori misoginis yang bersifat "merendahkan" perempuan. Dalam konteks asumsi berbasis metodologi, baik ilmu tafsir maupun ilmu hadis, banyak ditemukan persoalan mengenai penafsiran yang tepat terhadap ayat-ayat Alquran dan nilai keotentikan hadis-hadis tersebut, baik ditinjau dari segi 'amm dan khas, mujmal dan muqayyad, nâsikh dan mansûkh, maupun sanad dan matan sebuah hadis.

Hal yang lebih fatal lagi menurut Abou El Fadl adalah terlepasnya penafsiran tersebut dari asumsi-asumsi berbasis iman, nilai, dan akal yang harus menjadi pertimbangan dalam setiap penafsiran apa pun dalam studi-studi keagamaan, lebih-lebih adalah mengeluarkan fatwa-fatwa keagamaan yang menjadi rujukan dalam pengamalan yang digunakan masyarakat muslim dalam kehidupan keagamaan mereka (Abou El Fadl, 2003a: 325). 


\section{PENUTUP}

Fenomena sikap otoritarianisme atau berfatwa atas nama agama dan Tuhan dalam pemikiran Islam, menurut Abou El Fadl, banyak terjadi sebagaimana dibuktikan dalam penelitiannya yang memfokuskan pada kajian hukum Islam yang telah dilakukan oleh kalangan puritan Wahabi dalam lembaga fatwa CRLO yang banyak memberikan fatwa yang dianggap sangat bias jender, dengan metode tafsir dan pengambilan hukum (istinbât al-ahkâm) yang dalam kriteria Abou El Fadl bersifat otoriter. Proses ini terjadi karena "mendekati" teks tanpa melakukan "negoisasi" makna dan menyatakan suatu ketetapan makna hukum tanpa memberi ruang bagi munculnya interpretasi lain. Interpretasi seperti inilah yang disebut Abou El Fadl sebagai interpretasi yang bersifat otoriter atau dalam pemakaian ideologi penafsiran otoritarianisme. Karena tindakan tersebut mengambil "hak" Tuhan dan beralih mengambil posisi di mana sang penafsir menjadi "tentara-tentara" Tuhan yang mengklaim tafsirannya adalah otoritatif, absolut, dan sesuai dengan "kehendak" Tuhan.

Dalam konteks tersebut, Abou El Fadl menawarkan teori hermeneutika otoritatifnya, dalam rangka menghindarkan diri dari penafsiran otoriter. Sebagai sebuah metode tafsir dan hukum, hermeneutika Abou El Fadl sangat dapat membantu dalam menganalisis dan mendekati bahkan meluruskan penafsiran-penafsiran pada konteks penafsiran ayat-ayat atau hadis-hadis misoginis yang berkonotasi "perendahan" dan "penindasan" yang bias terhadap diri dan kehidupan perempuan. Tawaran Abou El Fadl ini menurut penyusun sangat besar kontribusinya terhadap sikap "kritisisme" bagi khazanah keilmuan Islam serta perangkat metodologi dalam proses penafsiran dan penggalian hukum Islam, terutama bagi pihak yang berurusan dalam lembaga fatwa seperti MUI dan ormas-ormas Islam, seperti Bahsul Masa'il NU, Majelis Tarjih dan Tajdid Muhammadiyah, Dewan Hisbah Persis, dan lembaga fatwa ormasorams lain seperti Perti, MMI, Al-Irsyad, Al-Washliyah, dan sebagainya.

\section{DAFTAR PUSTAKA}

Abou El Fadl, Khaled M. 2003a. Speaking in God's Name: Islamic Law, Authority, and Women. Oxford: Oneworld Publications. 
. 2003b. Melawan Tentara Tuhan: Yang Berwenang dan Sewenangwenang dalam Wacana Islam. Alih bahasa oleh Kurniawan Abdullah. Jakarta: Serambi Ilmu Semesta.

. 2004. Atas Nama Tuhan: Dari Fikih Otoriter ke Fikih Otoritatif. Alih bahasa oleh R. Cecep Lukman Yasin. Jakarta: Serambi Ilmu Semesta.

Abû Zayd, Nasr H $\square$ amîd. 1994. Naqd al-Khitâb al-Dînî, Kairo: Sina li alNashr.

Abdullah, Amin. 2004. "Pendekatan Hermeneutik dalam Studi Fatwa-fatwa Keagamaan", dalam kata pengantar Khaled M. Abou El Fadl, Atas Nama Tuhan: Dari Fikih Otoriter ke Fikih Otoritatif. Alih bahasa oleh R. Cecep Lukman Yasin. Jakarta: Serambi Ilmu Semesta.

Arkoun, Mohammed. 1994. Rethinking Islam: Common Questions, Uncommon Answers. Trans. Robert D. Lee. Oxford: Westview. . 2002. Al-Fikr al-Ushûlî wa Istihâlat al-Ta'sîl: Nahwa Târikh Âkhar li al-Fikr al-lslâmî. Alih bahasa oleh Hasyim Shalih. Beirut: Dâr al-Sâq.

Asmin, Yudian W. 2001. "Hassan Hanafi Mujaddid Abad Ke-15", dalam Kata Pengantar buku Hassan Hanafi, Turas dan Tajdid: Sikap Kita terhadap Turas Klasik. Alih bahasa oleh Yudian W. Asmin. Yogyakarta: Titian Ilahi Press dan Pesantren Pascasarjana Bismillah Press.

Assyaukanie, A. Luthfi. 1998. "Tipologi dan Wacana Pemikiran Arab Kontemporer". Paramadina, Vol. I, No. I, Juli-Desember.

Billa, Mutamakkin. 2005. Kritik-kritik Khaled M. Abou El Fadl atas Otoritarianisme dalam Diskursus Hukum Islam Kontemporer. Tesis tidak diterbitkn. Yogyakarta: PPs UIN Sunan Kalijaga Yogyakarta.

Bleicher Josef. 2003. Hermeneutika Kontemporer: Hermeneutika Sebagai Metode, Filsafat, dan Kritik. Alih bahasa oleh Ahmad Norma Permata.Yogyakarta: Fajar Pustaka Baru.

Misrawi, Zuhairi. 2005. "Khaled Abou El Fadl Melawan atas Nama Tuhan". Perspektif Progresif, Edisi Perdana Juli-Agustus.

Palmer, Richard E. 2003. Hermeneutika: Teori Baru Mengenai Interpretasi. Alih bahasa oleh Musnur Hery dan Damanhuri Muhammad. Yogyakarta: Pustaka Pelajar.

Romli, M. Guntur. 2005. "Membongkar Otoritarianisme Hukum Islam: Memahami Syari'at Sebagai Fikih Progresif”. Perspektif Progresif, Edisi Perdana Juli-Agustus.

Sirry, Mun'im A., 2005. "Islam, Teks Terbuka dan Pluralisme: Interpretasi atas Interpretasi Khaled Abou El Fadl". Perspektif Progresif, Edisi Perdana Juli-Agustus.

Misrawi Zuhairi. 2005. Wawancara dengan Khaled M. Abou El Fadl. Perspektif Progresif, Edisi Perdana Juli-Agustus. 